\title{
Model Farm Services Center Approach: An Implication to Boost Farmer's Yield
}

\author{
Rehmat Ullah', Muhammad Zafarullah Khan1, Kalim Ullah², Tahir Munir Butt ${ }^{3 *}$ \\ ${ }^{1}$ Department of Agricultural Extension Education and Communication, The University of Agriculture, \\ Peshawar, Pakistan \\ ${ }^{2}$ Pakistan Central Cotton Committee, Cotton Research Station, Dera Ismail Khan, Pakistan \\ ${ }^{3}$ College of Humanities and Development Studies, China Agriculture University, Beijing, China \\ Email: ${ }^{*}$ tahirmunir@uaf.edu.pk
}

Received 19 August 2015; accepted 15 September 2015; published 18 September 2015

Copyright (C) 2015 by authors and Scientific Research Publishing Inc.

This work is licensed under the Creative Commons Attribution International License (CC BY).

http://creativecommons.org/licenses/by/4.0/

(c) (7) Open Access

\section{Abstract}

The instant study was conducted to estimate the Model Farm Services Center's (MFSC) contribution in yield improvement of major crops/vegetables in district Dera Ismail Khan, Khyber Pakhtunkhwa, Pakistan, during the year 2014-15. Based on Sekaran sampling technique 306 respondents were selected and were personally interviewed through well prepared and pre-tested interview schedule. To find out the actual performance of yield improvement by Model Farm Services Center along with other repressors, step by step analysis was performed. The results of Wilcoxon Sign Rank Test showed significant improvement in yield of sugarcane, wheat, maize, rice and tomato by Model Farm Services Center. Pearson's correlation coefficient showed highly significant positive relation of sugarcane and wheat yield difference before and after Model Farm Services Center registration with MFSC. Ordinary Least Square Multiple-Regres- sion Model indicates that MFSC registration duration and landholding significantly define the variation in dependent variables at $1 \%$ and $5 \%$ level of significance respectively for sugarcane yield. Whereas solely Model Farm Services Center registration duration profoundly highly significantly $(P \leq 0.01)$ explains the variation in dependent variables in wheat yield.

\section{Keywords}

Model Farm Services Center, Sugarcane, Wheat, Pakistan

\section{Introduction}

Yield is a very complex attribute in any crop/vegetable or agriculture commodity and is influenced by various ${ }^{*}$ Corresponding author. 
factors including technologically sound farm operations, timely availability of inputs and production policies. To obtain this very purpose investment strategies, and ability to quantify the impact of policy is of critical importance. In this context, a key goal of agricultural research and policy is to close the gap between potential and average yield achieved in farmers' fields. Closing this yield gap will play an important role in increasing food production in the face of diminished gains in genetic yield potential, possible climatic changes, decreased resource availability, and stricter environmental standards [1]. On the other hand, [2] [3] argue that to compete the global market today, our farmers should have latest information regarding new techniques of farming, new methods of cultivation, new crops, seeds, pesticides, water management, marketing of the product, better government policies regarding agriculture and well export potential for their crops and after all provision of inputs (Seed, Fertilizers, Pesticides, machinery) on time. To achieve this, the farmers should be prompted to adopt improved and locally acceptable technology [4]. In the country most of the farmers are illiterate, socially excluded and poorly informed about the advancement in field of agriculture [5] [6] due to which they are not adroit in storage of their produce, lack technical know-how of getting good yiedl, processing for value addition and proper marketing. Thus the net result of farmer's plight is that agriculture seems to be an unviable economic activity to them.

Amongst above mentioned problems the lack of technical knowledge about production technologies of the major crops could be an important one. The available technology can be transferred through an effective extension approach, because agriculture extension is one of the means available to help alleviate poverty and improve food security. For effective dissemination of agricultural technology, in public sector, various extension approaches have been tried from time to time like village-AID program, Integrated rural Development Program (IRDP) [7], Inputs at Farmer's Doorsteps Approach and Training \& Visit System. These approaches were under heavy criticism, like too rigid, top down oriented, not responsive to farmers' needs, much expensive, ineffective in communicating with the farmers and were unable to meet the challenges of changing circumstances [8]. Keeping in view these drawbacks in 1999, Government of Khyber Pakhtunkhwa for the first introduced a new platform of Farm Services Center.

Farm Services Centers (FSCs) is an effective platform created for Sustainable agriculture in 1999 by Government of Khyber Pakhtunkhwa, Pakistan. Later on, in 2005 the Farm Services Centers were renamed as Model Farm Services Center (MFSC) and established at district level. The FSCs were then established at sub district levels as sub branches of MFSC to increase farmer's access to the quality inputs, technical advice and experience sharing. These centers were conceived with a view of organizing and empowering small farmers at a platform where full technical support of sub-sector of agriculture was available to them. The representatives of allied sectors of the Agriculture Department were kept under one roof and to provide one window services to the farmers in real sense, furthermore, facilitation of farmers with all major production inputs; seed, fertilizers, pesticides and machinery [9]. The basic concept of the FSC program was to provide a platform to the farming community, enabling them to resolve their issues of common interest, especially in agriculture collectively through developing linkages with Government Line Agencies (GLA). Their purpose is skill enhancement and to arrange input before-hand to be saved from any shortage and black marketing. It was a volunteer, public private partnership program [10]. These MFSCs has the authority that they take any action for the betterment of farming community and any person not less than 18 years old of age, having his own agricultural land, poultry farm, diary-farm, fish farm, involved in agribusiness activities, a tenant or having casual farm agricultural activities shall be eligible for membership of Model Farm Services Center. The MFSCs is then responsible to provide the following services to the registered member by paying an enrolment fee of Rs. 100/- and a membership fee of Rs. 500/- each; provision of certified seed, fertilizers, farm machinery, expertise, guidance regarding input provided, pesticides, enhance farmers knowledge and skills in farm management, planning and need assessment, boost the modernization of agriculture, Increase crop yields and Improve farmers livelihood. The present study was thus supposed to investigate whether MFSC was significantly contributing to improving farmer's livelihood through boosting their yields of various major crops.

\section{Materials and Methods}

\subsection{Universe of Study}

Present study was conducted in district Dera Ismail khan, Khyber Pakhtunkhwa, during the year 2015. It lies on $71.07^{\circ}$ longitude and $31.57^{\circ}$ latitude and $500 \mathrm{~m}$ above the sea level. This is the foremost suited region for production of wide range of agricultural crops and vegetables [11]. Descriptive Survey Research design was applied 
in this study.

\subsection{Research Design}

The descriptive survey [12] [13] research design was selected because primary purpose of the present study was to investigate the yield improvement of registered farmers by the assistance of MFSC.

\subsection{Selection of Sample Size and Respondents}

The total number of registered farmers in MFSC was 1500. According to [14] for population of 1500 the sample of 306 is appropriate. Based on [14] sampling technique from a given population, 306 respondents were selected randomly from registered farmers of MFSC throughout the district, and investigated through personal interview method. The farmers registered at least 2 years ago with MFSC were considered as the respondents of the study because less than 2 years of experience was insufficient for the study.

\subsection{Research Instrument (Interview Schedule)}

Well-structured and pre-tested questionnaire on 20 farmers was developed for data collection.

Cronbach's Alpha test [15] was calculated to check the reliability of the interview schedule by using Statistical Package for Social Sciences (SPSS) software. The overall value was 0.838 . Resultantly some minor amendments were incorporated in the interview schedule. Data was collected from the respondents by interacting with them at MFSC through personal interview method.

\subsection{Data Analysis}

Data collected was analyzed using Statistical Package for Social Sciences (SPSS) and Gretl software. To find out the actual factors involved in improvement of yield of various crop/vegetables, a series of tests were followed. Wilcoxon singed rank test (Equation (1)) was applied to find out whether there were significant differences in yield before and after registration with MFSC of various crops/vegetables. Next the yield differences were correlated (Equation (2)) with MFSC registration duration [16]. Those crops/vegetables which had significant correlation with MFSC registration duration were further subjected to application of multiple-regression model (Equation (3)). Multiple-Regression Model was applied to find out the extent of contribution of MFSC registration duration along with other independent variables. Prior to application of multiple-regression normality tests and heteroscedasticity test were also applied. It was thought necessary because the consequence of heteroscedasticity led to an unbiased and inefficient estimate of the coefficients.

$$
\begin{gathered}
Z=\frac{T-\mu_{T}}{\sigma_{T}}=\frac{T-\frac{n(n+1)}{4}}{\sqrt{\frac{n(n+1)(2 n+1)}{24}}} \\
\rho_{X, Y}=\operatorname{corr}(X, Y)=\frac{\operatorname{Cov}(X, Y)}{\sigma_{X} \sigma_{Y}}=\frac{E\left[\left(X-\mu_{X}\right)\left(Y-\mu_{Y}\right)\right]}{\sigma_{X} \sigma_{Y}} \\
Y=++\beta_{1} X_{1}+\beta_{2} X_{2}+\beta_{3} X_{3}+\cdots+\beta_{n} X_{n}+e
\end{gathered}
$$

where $Y$ is the predicted value of the dependent variable, "_, is the $y$ intercept (the value of " $Y$ " when all the " $X$ " values are zero), " $X \mathrm{~s}$ ” represents various independent variables and $\beta \mathrm{s}$ are the regression coefficients assigned to different independent variables. These denote the amount of change in the dependent variables for a unit change in the independent variables. The symbol " $e$ " denotes the error term, which indicates the proportion of unexplained variance in the dependent variables. The point of regression is to appear at the set of " $\beta$ " values, called regression coefficient for the independent variables that bring the " $Y$ " values predicted from the equation as close as possible to the $y$ values acquired by measurement. Associated with multiple regressions is $\mathrm{R}^{2}$, multiple correlations, which is the percent of variance in the dependent variable, explained jointly by all of the independent variables [17]. The implicit form of the model thus:

$Y=$ Sugarcane Yield 


$$
\begin{aligned}
& X_{1}=\text { Age } \\
& X_{2}=\text { Literacy Status } \\
& X_{3}=\text { Landholding } \\
& X_{4}=\text { Farming Experience } \\
& X_{5}=\text { MFSC Registration Duration } \\
& Y=\text { Wheat Yield } \\
& X_{1}=\text { Age } \\
& X_{2}=\text { Literacy Status } \\
& X_{3}=\text { Landholding } \\
& X_{4}=\text { Farming Experience } \\
& X_{5}=\text { MFSC Registration Duration }
\end{aligned}
$$

\section{Results}

\subsection{Wilcoxon Sign Rank Test of Crops/Vegetables Yield before and after Registration with MFSC}

Data in Table 1 shows the results of Wilcoxon singed rank test of various crops/vegetables. 214 respondents harvested increased sugarcane yield after getting registered with MFSC. 12 respondents got low yield whereas 8 ties were observed where no increase or decrease was found. The overall difference of sugarcane yield before and after registration with MFSC was highly significant $(\mathrm{P} \leq 0.01)$ with average increase of 13.087 maunds/acre (1292.9 kg/ha). Similarly about 260 respondents got increase in wheat yield after getting registered with MFSC. 16 respondents got decrease in their yield whereas 24 respondents neither got increase nor decrease in their yield after getting registered with MFSC. The overall mean differences of wheat yield before and after registration with MFSC was highly significant $(\mathrm{P} \leq 0.01)$ with an average increase of 1.588 maunds/acre $(157 \mathrm{~kg} / \mathrm{ha})$. Majority of the respondents (195) got increase in their maize yield after registration with MFSC whereas some negative ranks were also observed i.e. 11 respondents got decrease in yield. About 32 respondents got similar results of yield before and after getting registered with MFSC (Table 1). Over all highly significant $(\mathrm{P} \leq 0.01)$ increase was observed with average increase of 0.52 maunds/acre $(51.4 \mathrm{~kg} / \mathrm{ha})$. It was also observed that 71 out of 79 respondents got highly significant increase in their rice yield after getting registered with MFSC. The overall

\begin{tabular}{|c|c|c|c|c|c|c|c|c|}
\hline Crops/Vegetable & $\begin{array}{c}\text { Positive } \\
\text { Ranks }\end{array}$ & Mean & $\begin{array}{c}\text { Negative } \\
\text { Ranks }\end{array}$ & Mean & Ties & Total & Z-Score & Prob. \\
\hline Sugarcane & 214 & 115.91 & 12 & 70.5 & 8 & 234 & -12.225 & 0.000 \\
\hline Wheat & 260 & 140.13 & 16 & 112 & 24 & 300 & -13.089 & 0.000 \\
\hline Maize & 195 & 101.95 & 11 & 130.95 & 32 & 238 & -10.846 & 0.000 \\
\hline Rice & 71 & 36 & 0 & 0 & 8 & 79 & -7.344 & 0.000 \\
\hline Tomato & 62 & 36.4 & 8 & 28.5 & 12 & 82 & -5.966 & 0.000 \\
\hline Gram & 21 & 11.33 & 7 & 24 & 6 & 34 & -0.799 & 0.424 \\
\hline Onion & 70 & 42.24 & 29 & 68.74 & 29 & 128 & -1.687 & 0.92 \\
\hline
\end{tabular}
difference in rice yield before and after getting registered with MFSC was highly significant $(\mathrm{P} \leq 0.01)$ i.e. 0.628 maunds/acre (62 kg/ha). About 62 respondents got increase in tomato yield as a consequence of getting registered with MFSC while 12 respondents got similar results before and after getting registered with MFSC. Only 8 respondents got decrease in tomato yield. The overall difference was highly significant $(\mathrm{P} \leq 0.01)$ with average increase of 1.09 maunds/acre (107.69 kg/ha). Furthermore gram yield and onion yield were non-significantly increased after MFSC registration.

\subsection{Pearson's Correlation Coefficient of Yield Difference and MFSC Registration Duration}

Results in Table 2 shows Pearson's product moment correlation coefficient of crops yield differences and MFSC registration duration. Data in Table 2 depicts that there was highly significant $(\mathrm{P} \leq 0.01)$ positive correlation

Table 1. Wilcoxon sign rank test of crops/vegetables yield before and after registration with MFSC. 
Table 2. Pearson’s correlation coefficient of yield difference and MFSC registration duration.

\begin{tabular}{cccc}
\hline Yield Difference & Mean Difference (Maunds/acre) & “r” Value & Probability \\
\hline Sugarcane & 13.087 & 0.497 & 0.000 \\
Wheat & 1.588 & 0.81 & 0.002 \\
Maize & 0.52 & -0.105 & 0.105 \\
Rice & 0.628 & 0.40 & 0.723 \\
Tomato & 1.09 & 0.124 & 0.265 \\
Gram & 0.310 & 0.218 & 0.216 \\
Onion & 0.088 & -0.08 & 0.542 \\
\hline
\end{tabular}

between MFSC registration duration and sugarcane yield improvement. Highly significant $(\mathrm{P} \leq 0.01)$ positive correlation was also observed among wheat yield difference and MFSC registration duration with " $r$ " value of 0.81. Non-significant correlation was observed among rice, tomato and gram with MFSC registration duration though the relation was positive. Non-significant correlation in maize and onion might be attributed to the yield improvement of newly registered respondents.

\subsection{Multiple-Regression of Sugarcane and Wheat Yield after MFSC Registration with Independent Variables}

Normality of residuals is only required for valid hypothesis testing, that is, the normality assumption assures that the p-values for the t-tests and F-test will be valid. Ordinary Least Square (OLS) regression merely requires that the residuals (errors) be identically and independently distributed. Normality residual graphs (Figure 1, Figure 2) show that the data for both sugarcane and wheat were normally distributed with probability of 0.001 and 0.000 respectively.

The assumption of the homoscedasticity of the classical linear regression model is that the variance of each disturbance term $\mu i$ for the chosen values of the dependent variables is a constant number equal to $\sigma^{2}$. Symbolically it can be written as: $E\left(\mu i^{2}\right)=\sigma^{2} \quad i=1,2, \cdots, n$. If the aforementioned assumption is violated then it will lead to a problem of heteroscedasticity, which means that variance of the error term will no more remain constant. The consequence of heteroscedasticity is an unbiased but inefficient estimate of the coefficients. The results of the variances which may be small or large, leading to Type I or Type II error in the presence of heteroscedasticity. Heteroscedasticity is mainly present in cross sectional data as ours, than timeseries data (Gujarati, 2009). For this purpose two tests were followed; Whitney $U$ test for heteroscedasticity follows $\chi^{2}$ distributions. The estimated p-value for sugarcane was 0.734 whereas 0.09 for wheat and statistically insignificant. Thus the null hypothesis of homoscedasticity was accepted. Breusch-Pagan test for heteroscedasticity also follows $\chi^{2}$ distributions. The estimated p-value was 0.08 whereas 0.07 for sugarcane and wheat and statistically insignificant. Thus the null hypothesis of homoscedasticity was accepted. Aforementioned results reinforce our hypothesis of homoscedasticity which leads to the application of multiple-regression model for sugarcane and wheat. Similar tests were also applied for the other crops/vegetables (maize, rice, gram, tomato and onion) but due to heteroscedasticity problem multiple regression was not performed. The results shown in Table 3 and Table 4 revealed that MFSC registration duration had highly significant contribution in sugarcane and wheat yield. It means that with unit increase in duration of MFSC had increased sugarcane yield up to 0.13 maunds/acre (12.84 kg/ha) and 0.46 maunds/acre (45 kg/ha) in wheat.

The model for calculating sugarcane and wheat yield with R-square adjusted value of 0.603 and 0.57 respectively thus obtained are as follow.

Sugarcane Yield $=6.20+0.004($ Age $)+((-0.006)($ Literacy $))+0.01$ (Landholding $)+0.002($ Farming Experience) +0.13 (MFSC Registration Duration)

Wheat Yield $=2.60+0.001($ Age $)+((-0.012)($ Literacy $))+((-0.0084)($ Landholding $))+((-0.031)($ Farming Experience) $)+0.46$ (MFSC Registration Duration) 


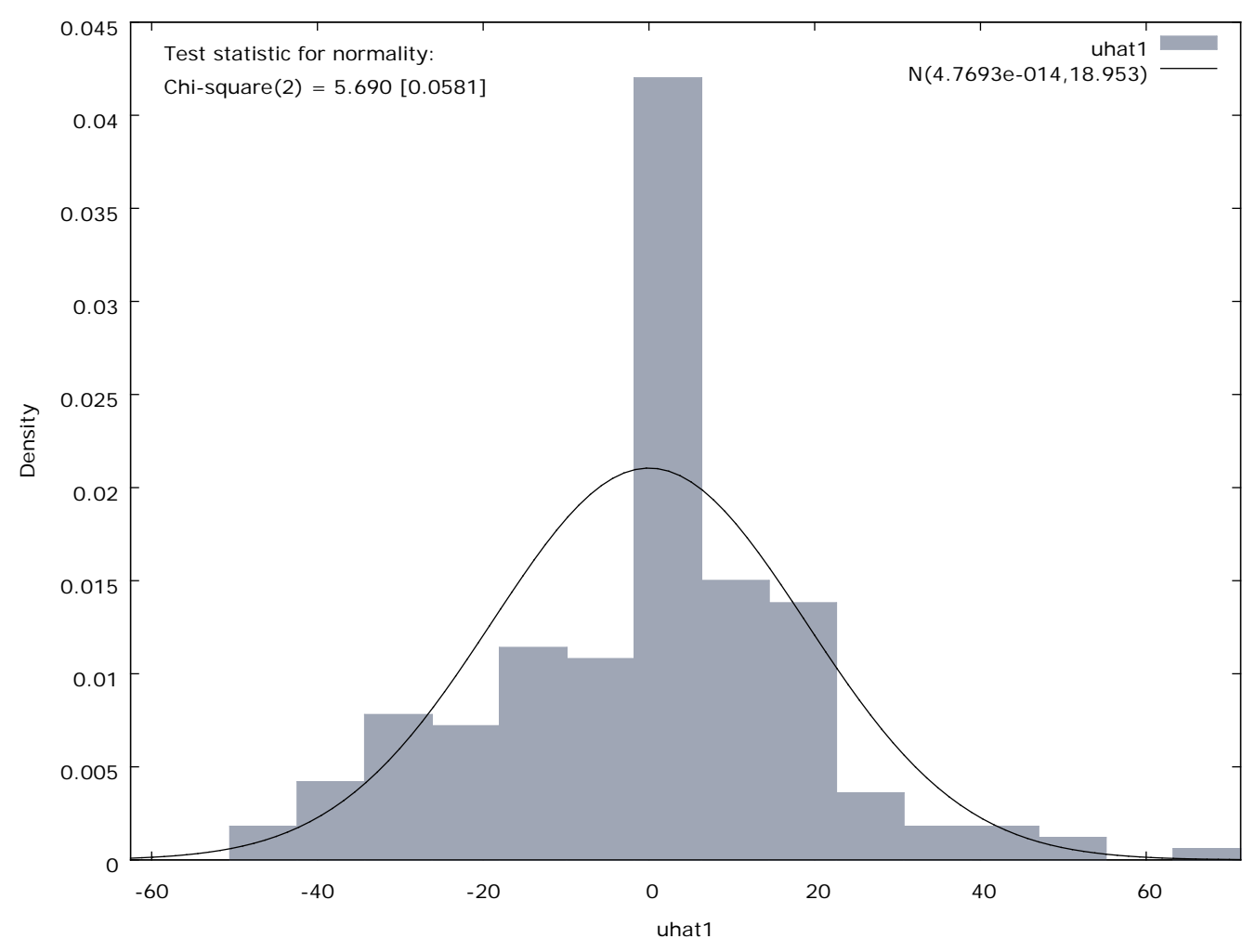

Figure 1. Normality residual graph of sugarcane yield after MFSC After MFSC.

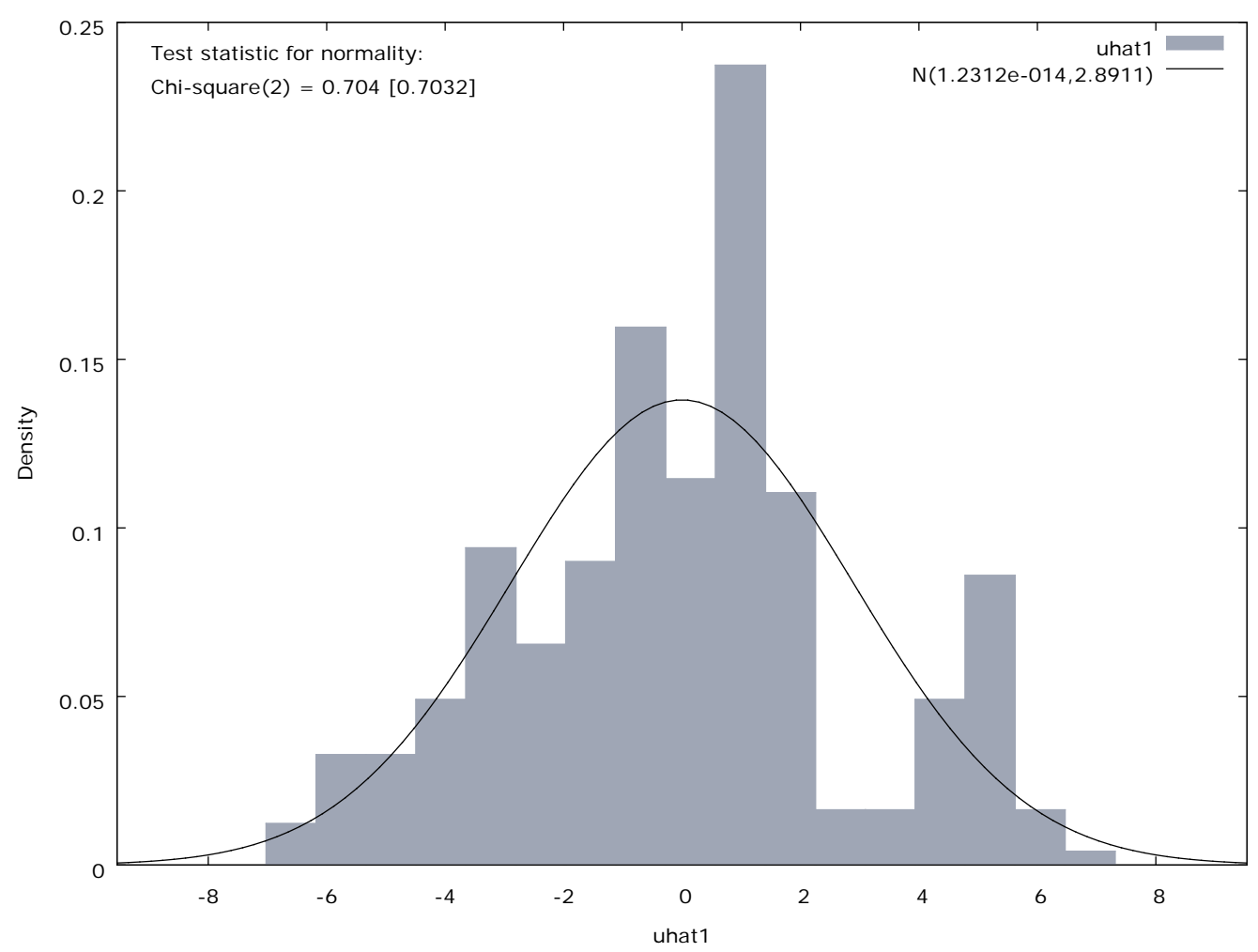

Figure 2. Normality residual graph of wheat yield. 
Table 3. Multiple regression of sugarcane yield after MFSC and independent variables.

\begin{tabular}{cccc}
\hline Independent Variables & Coefficient & Std. Error & t-ratio \\
\hline Constant & 6.20 & 0.037 & $167.60^{* *}$ \\
Age & 0.004 & 0.010 & 0.43 \\
Literacy Status & -0.006 & 0.007 & -0.83 \\
Landholding & 0.01 & 0.004 & $1.98^{*}$ \\
Farming Experience & 0.002 & 0.007 & 0.43 \\
MFSC Registration Duration & 0.13 & 0.008 & $16.55^{* *}$ \\
\hline${ }^{*}$ and $^{* *}$ indicates significance at 0.05 and 0.01 level of probability respectively, -square $=0.611$, Adjusted R-square $=0.603$, F stat $=0.000$.
\end{tabular}

Table 4. Multiple regression of wheat yield after MFSC and independent variables.

\begin{tabular}{cccc|}
\hline Independent Variables & Coefficient & Std. Error & t-ratio \\
\hline Constant & 2.60 & 0.139 & $18.72^{* *}$ \\
Age & 0.001 & 0.031 & 0.051 \\
Literacy Status & -0.012 & 0.018 & -0.64 \\
Landholding & -0.0084 & 0.012 & -0.71 \\
Farming Experience & -0.031 & 0.022 & -1.4 \\
MFSC registration duration & 0.46 & 0.024 & $19.76^{* *}$ \\
\hline
\end{tabular}

${ }^{* *}$ indicates significance at 0.01 level of probability, -square $=0.577$, Adjusted R-square $=0.57, \mathrm{~F}$ stat $=0.000$.

\section{Discussion}

MFSC had played its role and improved the yield of all the crops/vegetables observed. Improvement in yield was recorded on account of supply of inputs, machinery and guidance regarding crop/vegetable management by MFSC [18]. The present system enables farmers to buy quality inputs at reasonable wholesale rates. Research studies showed that when quality inputs were made available at reasonable prices, the yield got increased [19] [20]. Maximum improvement was recorded in wheat, sugarcane, maize and rice in comparison to other crops. Increase in these crops particularly wheat might be attributed to the seed farms of Agricultural Extension Department which is mainly focused on seed production of wheat crop. These seed farms provide better quality seed to MFSC well on time. Due to the same reason maximum respondents collected the wheat seed from MFSC. Very few respondents regarding all the crops/vegetables were observed who harvested low yield even after registration which might be due to the reason that they had not properly visited the MFSC once registred. Thus they might not obtained the inputs or farm implements which reduces their yield. The repercussions of increased yield might be attributed to the gigantic task being accomplished by MFSC i.e. due to farming skills provided by MFSC, timely suggestions and empowerment in skills of proper crop management, access to quality inputs including best varieties which improved their yield.

\section{Conclusion}

The findings revealed that MFSC played a vital role in yield improvement of sugarcane, wheat, maize, rice and tomato. Thus rampant scope of MFSC was due to the reason that MFSC registration duration had a significant contribution in improvement of yield and bridging the gap of potential yield of registered farmers. So the government should offer programs for awareness among the farmers to register themselves with MFSC in order to learn modern techniques of farming to cope with the problem of food insecurity. Similar studies need to be replicated in other MFSCs in the province.

\section{References}

[1] Cassman, K.G., Dobermann, A., Walters, D.T. and Yang, H. (2003) Meeting Cereal Demand While Protecting Natural 
Resources and Improving Environmental Quality. Annual Review of Environment and Resources, 28, 315-358. http://dx.doi.org/10.1146/annurev.energy.28.040202.122858

[2] Saadi, H., Madhei, K.N. and Movahedi, R. (2008) Surveying on the Wheat Farmers Access and Confidence to Information and Communication Channels (ICCs) about Controlling Eurygaster integriceps in Hamedan Province, Iran. American Journal of Agricultural and Biological Sciences, 3, 497-501. http://dx.doi.org/10.3844/ajabssp.2008.497.501

[3] Singh, R., Priya, A. and Singh, P. (2011) Role of ICT in Rural Empowerment. Researcg Journal of Social Science and Management, 1, 52-65.

[4] Hassan, M. (2000) Role of AKRSP in Dissemination of New Agriculture Technologies in Gilgit. Msc (H) Thesis, Department of Agricultural Extension Education and Communication, NWFP Agricultural University, Peshawar.

[5] Zakar, M.Z. (2007) Development of Farmers Competencies through Information Technology in the District Sheikhupura. An Unpublished Project Report Submitted to HEC by the Department of Sociology, University of the Punjab, Lahore.

[6] Khan, M.Z., Javidullah, S. Ahmad and Qasim, M. (2012) Assessing Professional Capabilities of Agriculture Officers for Weed Control: A Case Study of Khyber Pakhtunkhwa-Pakistan. Pakistan Journal of Weed Science, 18, 79-90.

[7] World Bank (2003) Operationalizing Agricultural Extension Reforms in South Asia-A Case of Pakistan. Country Paper: Regional Workshop, Delhi.

[8] Butt, T.M., Mahmood, K. and Muhammad, S. (2005) Working of Commodity Specialized Extension Approach Followed by Sugar Mills in Faisalabad-Pakistan. Journal of Agriculture \& Social Sciences, 252-254.

[9] Haq, I.U., Ahmad, M., Ali, T. and Zafar, M.I. (2009) An Analysis of Farm Services Centers (FSC) Approach Launched For Agricultural Extension In NWFP Pakistan. Pakistan Journal of Agriculture Sciences, 46, 69-72.

[10] Dad, A., Nizammi, E. Haldimann and Muhammad, R. (2007) Farm Services Centers: An Alernative Approach to realizing Potential. Agriculture Livestock, Diary Development and Cooperatives, Government of Khyber Pakhtunkhwa.

[11] Saleem, M.A., Jan, F.A., Qureshi, M.I. and Khattak, L. (2011) Linkage Financial Market and Farm \& Farmers Features for Adoption of New Farm Technology, a Case Study of D. I. Khan District of Khyber Pakhtunkhwa, Pakistan. Gomal University Journal of Research, 27, 69-76.

[12] Trochim, W. (2000) The Research Method Knowledge Base. 2nd Edition, Atomic Dog Publishing, Cincinnati.

[13] Khooharo, A.A. (2008) A Study of Public and Private Sector Pesticide Extension and Marketing Services for Cotton Crop. PhD Dissertation, Department of Agricultural Education, Extension \& Short Courses, Sindh Agriculture University, Tandojam, 42.

[14] Sekaran, U. (2003) Research Methods for Business. Harnitage Publishing Services, New York.

[15] Cronbach, L.J. (1951) Coefficient Alpha and the Internal Structure of Tests. Psychometrika, 16, 297-334. http://dx.doi.org/10.1007/BF02310555

[16] Chaudhry, S.M. and Kamal, S. (2009) Introduction to Statistical Theory (Part-1). IlmiKitabKhana Publishers, Lahore.

[17] Gujarati, D.N. and Porter, D.C. (2009) Basic Econometrics. 5th Edition, McGraw Hill Inc., New York.

[18] Haq, I.U., Hassan, M.S., Shah, N. and Chhachhar, A.R. (2013) Paradigm Shift from Conventional Agricultural Extension to Public-Private Partnership Extension in Khyber Pakhtunkhwa, Pakistan. Journal of Applied Sciences and Agriculture, 8, 1155-1160.

[19] Mesic, Ž., Žutinicand, Đ. And Wibberley, J. (2007) Rural Technology Transfer in Transition Economies in Croatia. Under Project Agro Economic Policy Analysis of the New Member States, the Candidate States and the Countries of the Western Balkan. CEEC Agri Policy.

[20] Reman, G., Vincze, M., Kölcsey, A. and Kerekes, K. (2007) Rural Technology Transfer in Transition Economies in Romania. Under Project Agro Economic Policy Analysis of the New Member States, the Candidate States and the Countries of the Western Balkan. CEEC Agri Policy. 